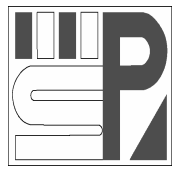

Science Press
Journal of Arid Land

2012, 4(3): 260-270

doi: 10.3724/SP.J.1227.2012.00260

jal.xjegi.com; www.chinasciencejournal.com

\title{
Trends and abrupt changes in surface vapor content over Tarim Basin during the last 50 years
}

\author{
HongJun $\mathrm{LI}^{1 *}$, WeiYi MAO${ }^{2}$, Yong $\mathrm{ZHAO}^{1}$, MinZhong WANG ${ }^{1}$, Wen $\mathrm{HUO}^{1}$ \\ ${ }^{1}$ Institute of Desert Meteorology, China Meteorological Administration, Urumqi 830002, China; \\ ${ }^{2}$ Xinjiang Climate Center, China Meteorological Administration, Urumqi 830002, China
}

\begin{abstract}
The surface vapor content has a close correlation with the generation of precipitation. Based on the atmospheric circulation data and surface vapor content data from 37 weather stations across the Tarim Basin during 1961-2010, the paper analyzed the vapor variation trend, period, abrupt changes and their causes. The results show that the increase trend of surface vapor content over the Tarim Basin mostly conforms with the average trend coefficient of 0.48 . There were 3 centers displaying a trend of high vapor increase and 3 centers displaying a low vapor increase. These centers were distributed in strips and blocks across the basin from northeast to southwest. Notable inter-decadal variations in annual and seasonal vapor contents occurred in the Tarim Basin during the 50 years of the study period, with more vapor after the mid-1980s and less vapor in the 1960s and the 1970s. The significant increase in vapor content in the 50 year period occurred mostly in the 1980 s and the 1990s. The increasing trend across the four seasons was strongest in summer, reaching 0.43 , and weakest in spring. Great variations existed between the spring trend and the annual, summer, autumn and winter trends. During the 50-year study period, there are distinguishable periods of 4-6 years and 8-10 years in which the annual and seasonal vapor contents varied alternately between low and high concentrations. The annual vapor content and that of the four individual seasons all changed abruptly in about the mid-1980s $(\alpha<0.05)$. The west wind circulation, Tibetan Plateau circulation and the annual mean temperatures of the Tarim Basin are the main factors that influenced the surface vapor content over the study area, of which the Tibetan Plateau circulation may be the most important one.
\end{abstract}

Keywords: surface vapor content; climate factors; periodic variation; abrupt change; Tarim Basin

Water vapor content directly affects the generation of precipitation, and the surface vapor content has a close positive correlation with the whole content of water vapor in the air (Karalis, 1974; Yang et al., 2002; Zhang, 2004). Many researches have been undertaken in water vapor conditions, sources, directions of movement and convergence regarding the formation of heavy rain, and in the relations between these factors and the rainy season and rain belts in the east, south and low-latitude regions of China (Xu, 1958; Huang et al., 1998; Niu, 2004; Zhou, 2005; Jian, 2006). However, due to the limitation of available data and computing technologies, it was not until the 1990s that the study on water vapor in Northwest China began to be paid much attention to (Cui, 1994; $\mathrm{Li}$ and
Xie, 1997; Wei et al., 2000; Wang et al., 2003; Wang et al., 2006). Since the latter half of the $20^{\text {th }}$ century, precipitation in the Tarim Basin increased noticeably due to global warming (Liu et al., 2005; Fan et al., 2011) and the climate changed from 'warm and dry' to 'warm and humid' in the western part of the basin (Hu et al., 2002; Shi et al., 2002). The Tarim Basin had witnessed more floods than previously (Jiang and Yang, 2004). The water vapor conditions that resulted in these changes have changed markedly. By studying the water vapor transport over the Tarim Basin, Lin et al. (1992) stated that the water vapor in Northwest China is primarily supplied by the west wind circula-

Received 2011-11-02; accepted 2012-04-16

"Corresponding author: HongJun LI (E-mail: lihj@idm.cn) 
tion and the South Asian monsoon, while the water vapor over the Tarim Basin comes mostly from the Arabian Sea, having traversed the Karakoram Mountain and Pamir Plateau. The study by Wang (2006) revealed that the $600 \mathrm{hpa}$ wind field over the Tarim Basin is a positive divergence area with clear downdrafts, forming strong divergence in the low-level atmosphere and resulting in negative convergent transport of water vapor in the corresponding atmosphere layer. Yu et al. (2003) found, from his research on the 43-year mean water vapor content of the whole atmosphere layer, that the Tarim Basin is a relatively high-value center of water vapor in Northwest China. During the period from the 1960s to the 1990s, water vapor content in the entire Xinjiang region including the Tarim Basin was in a trend of continuous increase, especially in the 1990s, when the increasing trend was more evident. Generally speaking, the above-mentioned studies on the water vapor content over the Tarim Basin were essentially based on global atmospheric circulation data, but the resolutions of these data tend to be poor, and insufficient to interpret the variations in the surface vapor condition in such a complex landform area as the Tarim Basin. Moreover, those research results differ as well, unable to reflect the trends and abrupt changes of local vapor content. Up to now, few researchers have used any vapor data with higher resolutions from the observation stations in the
Tarim Basin, nor have any studies been done on the abrupt changes in the surface vapor content over the Tarim Basin. What's more, the relations between these changes and climate change need to be further explored. In this paper, the data of surface vapor content during the period 1961-2010 were obtained from 37 weather stations in the Tarim Basin. From these data, we quantitatively verified and judged the variations in trends, and the abrupt changes in surface vapor content in the 50-year period, and analyzed their correlations with climate change. These studies will be of importance in revealing the regularity of regional water vapor fluctuations to recognize the evolution of drought, and to optimize the utilization of the air water vapor resources.

\section{Study area and methods}

\subsection{Study area}

The Tarim Basin is situated in the hinterland of Eurasia $\left(75^{\circ}-91^{\circ} \mathrm{E}, 37^{\circ}-41^{\circ} \mathrm{N}\right.$; Fig. 1). It covers an area of $53 \times 10^{4} \mathrm{~km}^{2}$, being about $1,500 \mathrm{~km}$ in length and 600 $\mathrm{km}$ in width. It is the largest inland basin in China, in the typical warm temperate zone, and features a continental arid climate. It is surrounded by the Tianshan Mountains, Kunlun Mountains and Altun Mountains. The centre of the basin is the famous Taklamakan Desert, and from the center of the basin to oases, gobi,

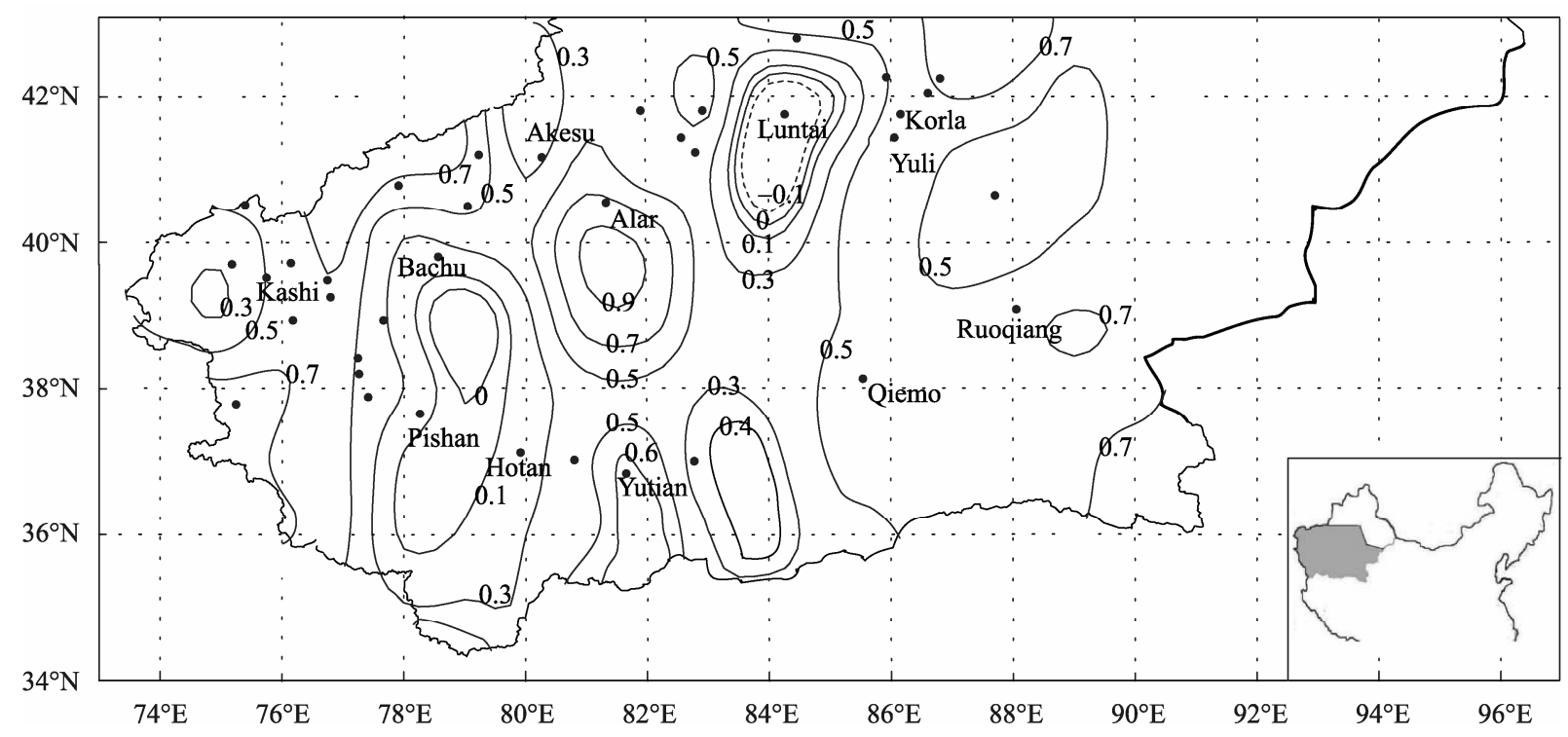

Fig. 1 The trend distribution of surface vapor contents over the Tarim Basin during 1961-2010 
and piedmonts, the elevation ranges from $800 \mathrm{~m}$ to $1,300 \mathrm{~m}$. In addition to a few inland rivers entering the basin, almost all water supplies are from precipitation. The precipitation water vapor is primarily carried by the west wind circulation from the Atlantic and Eurasia; the Arabian Sea vapor carried by the South Asian monsoon is another source of vapor which passes over the Kunlun Mountains. Because of the block of water vapor by high mountains, the Tarim Basin has a mean annual precipitation of less than $100 \mathrm{~mm}$ and a mean annual relative humidity of $49.8 \%$. The climate is very dry and sensitive to global climate change; furthermore the climate of the basin is wetting, which is different from the case in most neighboring regions $(\mathrm{Hu}$ et al., 2002; Shi et al., 2002). So the basin is an ideal region for the study of climate change in arid environments.

\subsection{Data and methods}

The surface vapor content refers to the pressure of water vapor in the atmosphere at 1.5 -meter height according to the specifications for surface meteorological observation (China Meteorological Administration, 2003), and it is given by calculating the measurement of psychrometer of weather stations. Based on the principle of homogeneity, integrity and comparability, we chose surface vapor content data for 1961-2010 from 37 weather stations out of a total of 58 stations in the Tarim Basin. The data were compiled by Xinjiang Meteorological Bureau. The detection of homogeneity and revision of the chosen vapor data (Wang et al., 2007) were further carried out. Data from 16 of the 37 stations are homogeneous, while there are abrupt changes in the data from the other 21 stations, with change points occurring mainly in the 1980s, especially in 1986 when abrupt change points occurred in the data from 15 stations. Man-made errors were excluded, leaving climate factors as the cause for the abrupt changes at the 21 stations. The data from these 21 stations are reliable. The regional $\left(30^{\circ} \mathrm{W}-70^{\circ} \mathrm{E}\right.$, $30^{\circ}-50^{\circ} \mathrm{N}$ ) west wind index (Li et al., 2008) was calculated by using NCEP/NCAR (National Centers for Environmental Prediction/National Center for Atmospheric Research) reanalysis data (Kalnay et al., 1996). The Tibetan Plateau circulation index comes from Chinese National Climate Center (Chinese Na- tional Climate Center, 2008). The trend lines were calculated using the ' 5 points and third-order smoothing' method (Wei, 1999); the trend values were obtained by the method of trend coefficient (Wei, 1999); the periodic analysis was performed using the real part of Morlet Wavelet Analysis (Wei, 1999); and the abrupt change tests on vapor, temperature and atmospheric circulation were performed using the Mann-Kendall (MK) abrupt change verification method (Fu and Wang, 1992). The method of data symmetrical extension was applied to eliminate wavelet marginal effects (Deng et al., 1997), with the data for every station extended for 150 years. Periods of less than one year were removed by anomaly filtering, and then, after wavelet transformation, the wavelet coefficients of the original 50 years of data were applied in the analysis. Before MK abrupt change test, the data were checked to eliminate auto-correlated effects (Partal and Ercan, 2006). The original data were then converted as $\left(x_{2}-r_{1} x_{1}, x_{3}-r_{1} x_{2}, \cdots, x_{n}-r_{1} x_{n-1}\right)$, where $x_{i}$ is original data, and $r_{1}$ is auto-correlated coefficient of lag time one year.

\section{Results}

\subsection{Spatial and temporal distribution of the trend in surface vapor content}

\subsubsection{Spatial distribution}

Figure 1 displays the spatial distribution of the trend in mean annual surface vapor content in the Tarim Basin. It can be seen that during 1961-2010 all the trends in vapor content over the Basin were $>0$ except at one or two stations (Fig. 1). According to statistics, the coefficient for the spatial mean trend across the Basin was 0.48 , and the increasing trends for about $75.7 \%$ stations were significant $(\alpha<0.05)$. Spatially, there were three centers with increasing high values, respectively located at Yutian in the south of the Basin, Yuli at the southern slope of the Middle Tianshan Mountains and Alar in the northwest of the Tarim Basin. The increasing trend amongst the high-value centers was strongest at Alar, with a top value of 0.84 , where the isolines of the variations were dense, indicating the trends vary to some great extent between the places within this area. The areas with minor increasing trends were mostly situated in the southwest of the Tarim Basin, with two 
low-value centers near Pishan and in Bachu county. However, the center with the minimum value was found at Luntai with a trend value of -0.28 . Therefore, the trends in the surface vapor content over the entire Tarim Basin appeared as alternating strips and blocks of high-value areas and low-value areas, running from northeast to southwest. The trend in decreasing vapor content at Luntai was not consistent with the increasing trend in the rest of the basin, which may be caused by a change in local circulation. Noticeable increases in southerly wind run have been recorded at Luntai since the 1980s, which is expected to bring much dry desert air to Luntai, further decreasing vapour content.

\subsubsection{Temporal distribution}

Figure 2 shows the annual variation and trend curves of the surface vapor content over the Tarim Basin. A study of the figure shows that the vapor content increased significantly during 1961-2010, and the mean trend coefficient was $0.648(\alpha<0.001)$. The vapor content for the last 24 years was larger than the 50 -year mean value, and most of the increases appeared in the years after 1987, the number of which accounts for $48 \%$ of the total years. The year 1998 recorded the highest value of vapor content, which was $7.8 \mathrm{hpa}$, whilst 1961 had a least vapor content of $6.2 \mathrm{hpa}$. The temporal distribution of the variation was divided into 3 periods. During the period 1960-1985, the annual vapor content was at a low level, fluctuating readily and having a weak tendency to grow more. In the mid and late periods of the 1980s, the vapor content increased with a strong upward trend; and the period after the late 1980s was the time with more vapor content and the increasing trend was strong, but after 2006 it tended to decline again. The four seasonal increasing trends during 1961-2010 were significant $(\alpha<0.01)$, although the intensity of the increasing trends varied with seasons. Summer was found to have the strongest increasing trend, reaching 0.43 , while autumn had the second strongest increasing trend, and spring had the weakest, being recorded at only 0.323 . The onset of annual increases in the vapor content occurred in the mid-1970s when the vapor content in spring began to show fluctuating increases. However, increases had begun in the other seasons (summer, autumn and winter) at as early as the end of the 1960s and the beginning of the 1970s. As for the fastest growing periods of vapor among the four seasons, spring was distinguished from the other three seasons.
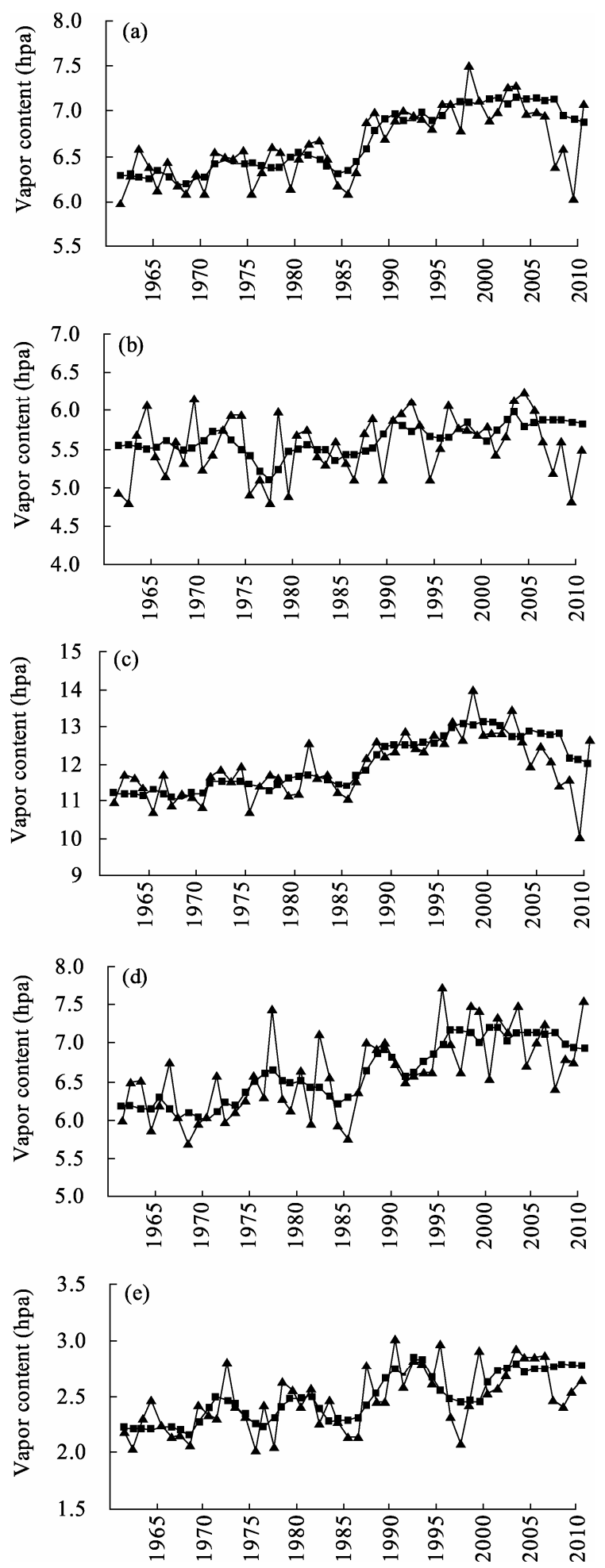

Fig. 2 The annual (a), spring (b), summer (c), autumn (d) and winter (e) variation trends of surface vapor contents over Tarim Basin during 1961-2010; triangles and squares along the lines indicate observed data and smoothed trends, respectively. 
In the springs of the mid-1970s to the early 1980s and the mid-1980s to the early 1990 s, the vapor content grew the fastest, whereas the vapor content in summers, autumns and winters of the mid-1980s to the early 1990s was recorded as increasing fastest. Based on the analysis of the evolving higher vapor content above, we found that the biggest increases across the four seasons mostly occurred in the period from the mid-1980s to the early 1990s. The lowest values of the vapor content emerged during the end of the 1960s to the middle of the 1970s, while the largest values appeared in the 1990s (Fig. 2). The surface vapor content has been increasing in the Tarim Basin since 1961, while the whole vapor content in Northwest China decreased during the 1960s and 1970s, and has increased since the 1980s ( $\mathrm{Yu}$ et al., 2003); there are similarities and differences between the two areas.

The annual and seasonal surface vapor contents over the Tarim Basin during 1961-2010 (Table 1) all show significant increasing trends except in spring $(\alpha<0.001)$, while their trend and trend strength are different between the decades. The trend in annual vapor content was negative between the 1960s and somewhat weak during the 1970s, but in the 1980s and 1990s it turned into a very distinct upward trend. In the 1980s the vapor content presented a strongest increasing trend with the value of 0.4702 , while in the $2000 \mathrm{~s}$ it began to decrease again with a value of -0.637 . In the springs of the 1960s and 1980s, the trend in vapor content was increasing, whereas in the other decades the trend was either unclear or negative. Summer surface vapor content showed either no obvious trends or negative trends in both the 1960s and 1970s, but trends turned positive in the 1980s and 1990s before becoming mostly negative in the 2000s. For autumn seasons, the 1960s and 2000s showed negative trends in surface vapor content, but in the other decades, the trends were positive. The winter seasons of the 1960s and 1980s had positive trends in the vapor content, and the other decades had negative trends. The annual and seasonal vapor trends were mostly positive in the 1980 s and 1990s; all vapor trends were negative in the 2000s. The significant increase of vapor content results from the accumulation of all decades' variations in the recent 50 years, with the greatest contribution coming from the increases in the 1980s and 1990s.

\subsection{Periodicity of vapor content variation}

Wavelet analysis reveals that the periodic characteristics of the variations of the surface vapor content were remarkable at inter-decadal scales in the Tarim Basin in different seasons and years (Fig. 3). The oscillation periodicity of annual vapor content in the past 50 years occurred primarily in 3-10 years, of which the 8 -year and 4-year periodicities were more notable in comparison with the others; the periodicity of 20 years was also obvious, but slightly weak in intensity. Moreover, the periodic variation of annual vapor content showed stage characteristics in different periodicities. The cycles of 8 and 4 years existed in the entire period of 50 years, with periods of higher and lower vapor content emerging by turn. After the start of the $21^{\text {st }}$ century, the intensity of the higher vapor content was weaker. The 8-10 year and 4-6 year cycles of the spring vapor oscillation were significant, and moreover, that of the 20-year period was obvious too, but a little weak in intensity. In the periods of 4 and 8 years, the higher-vapor periods and lower- vapor periods appeared to alternate, and the 20 -year periodic scale from the 1960 s to the $21^{\text {st }}$ century exhibited three clear periods of higher vapor and three periods of lower vapor. The 4-6 year, 8-year and 20-year cycles of the summer vapor content oscillation were more visible, and the three periodic belts in the last 50 years

Table 1 The decadal trend coefficient of surface vapor content over the Tarim Basin during 1961-2010

\begin{tabular}{ccccccc}
\hline & \multicolumn{3}{c}{ Period } \\
\cline { 2 - 6 } & $1961-1970$ & $1971-1980$ & $1981-1990$ & $1991-2000$ & $2001-2010$ \\
\hline Annual & -0.1601 & -0.2507 & 0.4702 & 0.3010 & $-0.6370^{*}$ \\
Spring & 0.3836 & -0.2793 & 0.1362 & -0.1572 & -0.5278 & $0.6481^{* *}$ \\
Summer & -0.4156 & -0.4588 & 0.3545 & 0.4446 & $-0.6660^{*}$ & 0.2177 \\
Autumn & -0.3861 & 0.2778 & 0.4646 & 0.4140 & -0.2556 & -0.4401 \\
Winter & 0.2353 & -0.0191 & 0.4736 & -0.2800 & $0.5651^{* *}$ \\
\hline
\end{tabular}

Note: ${ }^{*}$ and ${ }^{* *}$ denote significance at 0.05 and 0.001 level, respectively. 


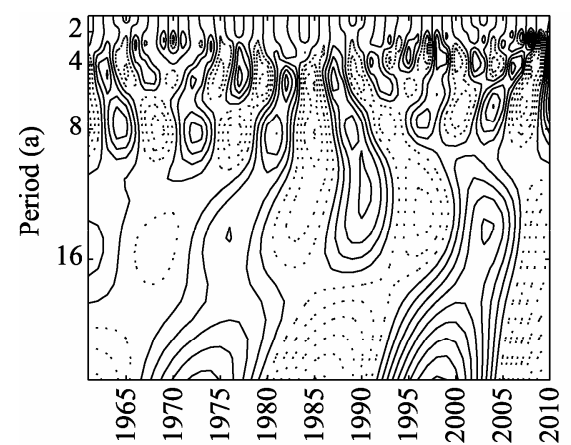

(a)

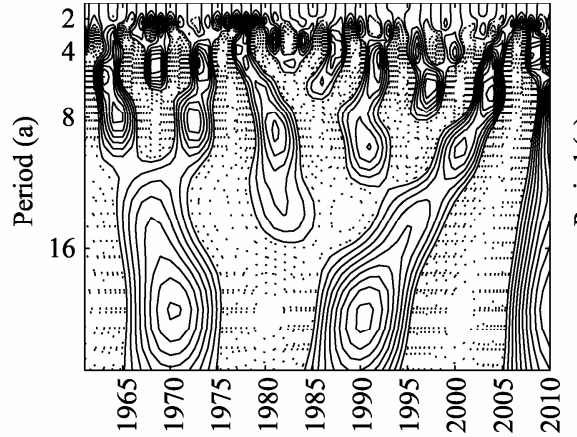

(b)

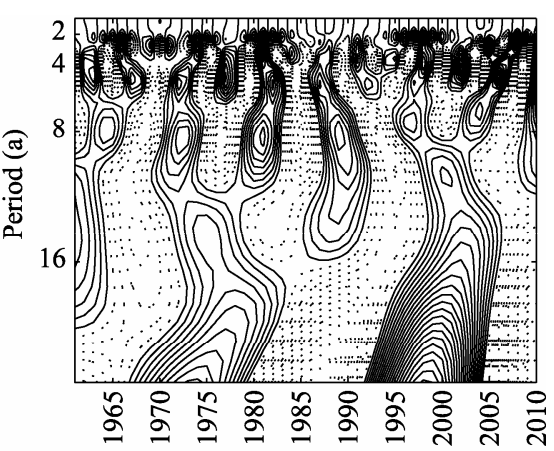

(c)

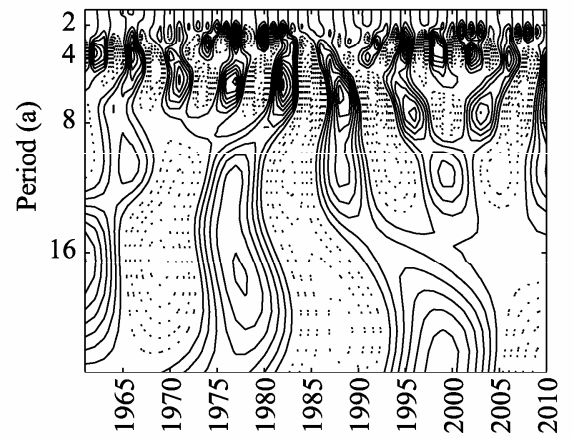

(d)

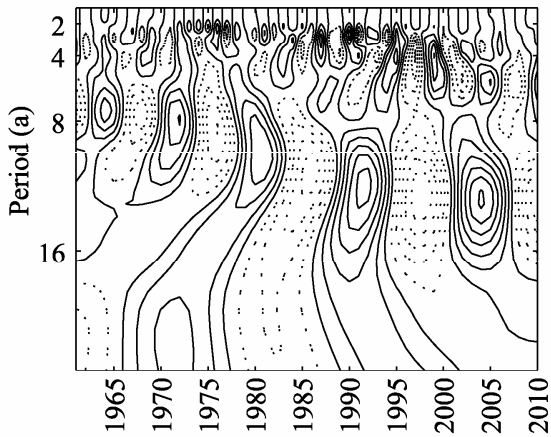

(e)

Fig. 3 The annual (a), spring (b), summer(c), autumn (d) and winter (e) wavelet analysis of surface vapor contents over the Tarim Basin during 1961-2010

had the obvious alternation of more vapor and less vapor, and the periodicity of 20 years became more and more obvious as time passed. The summers of the 1990s contained the periods of dramatically higher vapor content. The 4-year and 18-year cycles of the autumn vapor oscillation were very obvious, going up year by year gradually from 4 years to 8 years, and within all periodic scales there was very notable alternation of more vapor and less vapor. The variation of winter vapor oscillation in the 50-year period had a weak 4-year cycle, and before the 1980s the 8 -year cycle was clear, but after the 1980 s the cycles of 10 years and 16 years took their respective place.

\subsection{Abrupt change of surface vapor content}

In the last 50 years, the surface vapor content increased greatly over the Tarim Basin, which needs to be further analyzed to see if it has reached the abrupt change standard. The abrupt change diagram of the surface vapor content over the Tarim Basin (Fig. 4) revealed the trend of annual vapor content (Fig. 4a) was positive in most periods except the end of the 1960s, and after 1985 the trend of annual vapor content increased in all years. The crossing points of $\mathrm{cl}$ and c2 in Fig. 4a were seen in 1985, and after 1998 the tendency of increase became significant $(\alpha=0.05)$, which indicates the abrupt change in annual vapor content occurred in 1985. The trend of spring vapor content had always been positive after 1985, showing a fluctuant increasing trend, and after 2004 the increasing trend became significant $(\alpha=0.05)$, but the abrupt change happened in 1983. The trend and abrupt change were similar between the summer vapor content and the annual vapor content, and the abrupt change occurred in 1985. Beginning from the 1970s, the trend of increasing autumn vapor content fluctuated and it was in 1974 that the vapor content altered from decreasing to increasing trend; in 1990 the increasing trend became significant $(\alpha=0.05)$, and the abrupt change appeared in 1986. The increasing trend in winter vapor content started to fluctuate from the end of the 1960s, and in 1969 the trend turned from decreasing into increasing; in 1990 the increasing trend became significant $(\alpha=0.05)$ and the abrupt change occurred in 1986. 

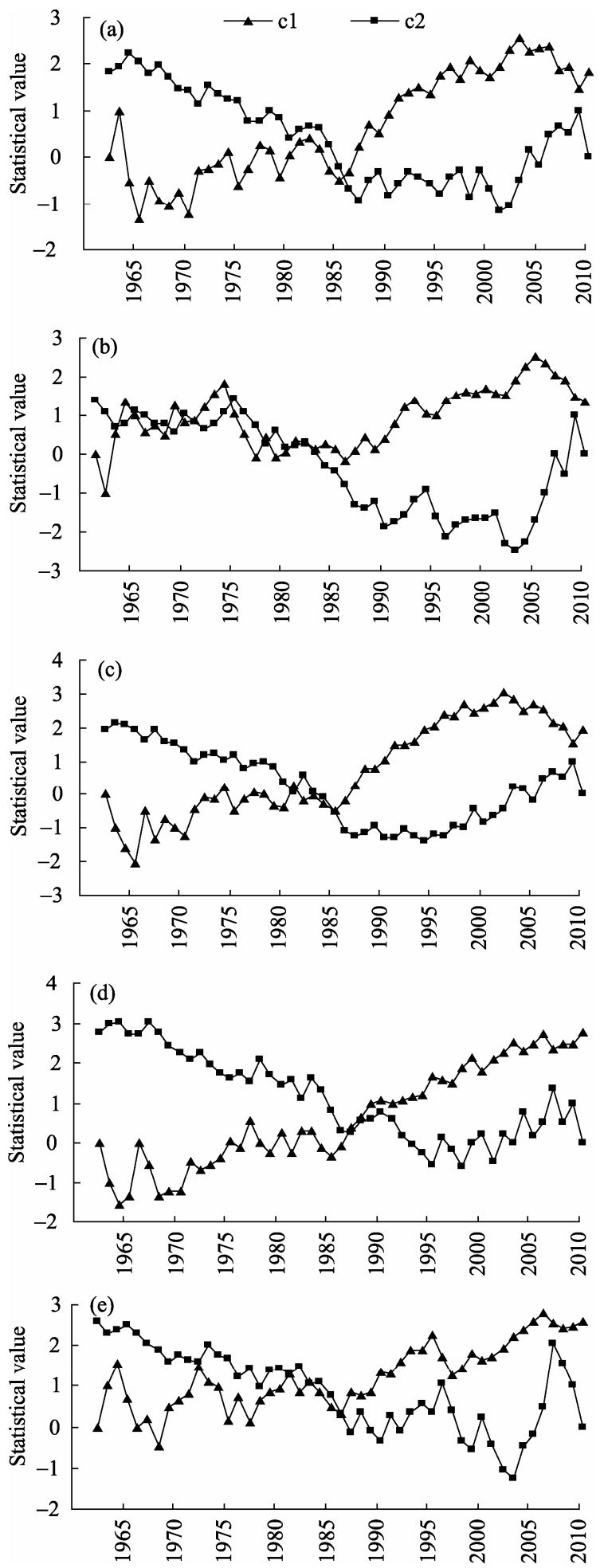

Fig. 4 The annual (a), spring (b), summer (c), autumn (d) and winter (e) abrupt change of surface vapor content over the Tarim Basin during 1961-2010. c1 and c2 represent statistical series in positive sequence and statistical series in reverse sequence, respectively.

\section{Discussion}

The sudden increase of surface vapor over the Tarim Basin in the mid-1980s was the result of global climate change and regional influences working together. Over the last one hundred years, the mean temperature and sea level pressure of the Northern Hemisphere changed in 3 big jumps, respectively in the 1920s, 1950s and at the end of the 1970s and beginning of the 1980s (Ai and Lin, 1995). The annual precipitation over the land at the high latitudes of the Northern Hemisphere increased slightly, however, this was offset by decreases in various latitude belts, resulting in abrupt global annual precipitation reduction in about 1978 (Shi and Chen, 2002). Since the 1980s, water vapor has increased in Central Asia and even northern Europe (Yu et al., 2002). The decadal sudden changes in precipitation and temperature at the end of the 1970s and beginning of the 1980s occurred in the rest of China during 1950-1997 (Lin et al., 1998; Ding et al., 2003). After the end of the 1970s, the water vapor increased in the middle of East China and decreased in the north and south of East China, while the situation was contrary during the 1950s-1970s (Huang et al., 2010). The increase in temperature and precipitation presented abrupt changes in warming and wetting in the Tarim Basin after the 1980s (Li et al., 2008). Global climate change has influenced the atmospheric circulation since the end of the 1970s. This has affected the supplementation, transportation and convergence of Tarim Basin water vapor, resulting in more water vapor transfer to and retention in the Basin. Temperature warming in the Basin, and over China in general, is advantageous to improving the capacity of the atmosphere to hold and transport water vapor. These, then, were the changes that caused the turning change or abrupt change of surface vapor content over the Tarim Basin in or near the 1980s.

\subsection{Relation between the surface vapor content and climate factors}

The increase of surface vapor content over the Tarim Basin is connected with the regional climate changes over the past 20 years. The change trend of annual mean temperature in the Tarim Basin began to fluctu- 
ate upwards from the mid-1970s, and in the early 1990s abrupt change occurred (Li et al., 2008). With the increase of temperature, the surface evapotranspiration strengthened, meanwhile, the vapor-holding capability of the warmer atmosphere increased too, and water vapor in the atmosphere increased. Water vapor content is the exponential function of temperature, correlated positively to temperature, and responds much more sensitively to climate warming than temperature. Therefore, the timing for vapor content to begin increasing and the year for the abrupt change of vapor content were earlier than those for temperature. The calculated correlations between annual, spring, summer, autumn and winter surface vapor content and the annual mean temperature in the Tarim Basin during 1961-2010 were 0.42, $0.10,0.29,0.48$ and 0.36, respectively. Except for the value for spring, the other values are significant $(\alpha=0.05)$, showing that the annual, summer, autumn and winter vapor contents are significantly correlated to the annual mean temperature in the Tarim Basin.

The increase of surface vapor content over the Tarim Basin is correlated to the global warming and atmospheric circulation changes. The surface vapor over the Tarim Basin primarily originates from the vapor evaporated from the Atlantic Ocean and Eurasia, which is transported into the basin by the west wind circulation (Lin et al., 1992; Cui et al., 1994; Dai et al., 2007). With global warming, the atmosphere receives more water vapor from the Atlantic Ocean and Eurasia, while the west wind circulation (represented by west wind index, range: $30^{\circ} \mathrm{W}-70^{\circ} \mathrm{E}, 30^{\circ}-50^{\circ} \mathrm{N}$ ) is strengthening and more able to transport increased water vapor into the Tarim Basin. The west wind circulation began to fluctuate upwards in the mid-1970s, and then appeared to change abruptly in the early 1980 s, during which time surface vapor content in Tarim Basin increased. The period of abrupt change in the surface vapor content was close to the time of change in the west wind circulation, which indicates that the variation of west wind circulation impacts the surface vapor content in the Tarim Basin. By calculation, the correlation coefficient between the annual, spring, summer, autumn and winter water vapor content and the west wind circulation index was $0.33,0.26,0.25,0.15$ and 0.36 , respectively. Of these, the values for the annual and winter correlations are significant $(\alpha=0.05)$, implying that the west wind circulation was significantly correlated to the annual and winter vapor content in the Tarim Basin.

The Tarim Basin is situated to the north of the Tibetan Plateau and is obviously affected by the plateau circulation. In warm years, the surface of the Tibetan Plateau is dominated strongly by heat, and the upward motion of the atmosphere over the plateau strengthens, causing the development of convergent upward motion from the convective low level to the north side of the plateau, where the vapor is concentrated and easily converted into precipitation (Qian et al., 2001). However, in colder years, the heat over the plateau surface is reduced, and the upward motion over the plateau is also weak. Under these conditions, strong sinking motion prevails over the north side of the plateau, resulting in dry years (Qian et al., 2001). The climate of the Tibetan Plateau has become warmer in the past decades (Lv et al., 2010). The trend of the Tibetan Plateau circulation (represented by Tibetan Plateau circulation index) began to fluctuate upwards in the mid-1970s and changed abruptly in the mid-1990s, which drove the strengthened upward motion of air over the plateau. Therefore, the Tarim Basin becomes moister than before. The correlation coefficient between the annual, spring, summer, autumn and winter surface vapor content over the Tarim Basin and the circulation index of the Tibetan Plateau was 0.52, 0.21, 0.42, 0.50 and 0.34 , respectively, of which the annual, summer, autumn and winter correlations are significant $(\alpha=0.05)$. Therefore, it is concluded that significant correlations exist between the surface vapor content in the Tarim Basin and the circulation over the Tibetan Plateau.

\subsection{Climate factors driving vapor content variation}

This study carried out linear correlation analyses between surface vapor content and climate factors (temperature, west wind circulation and the Tibetan Plateau circulation) to find the important factors whose variations were the main contributors to the increase and abrupt changes of surface vapor in the Tarim Basin. From the correlation coefficients between surface vapor content and climate factors (Table 2), clear positive correlations between surface vapor content and temperature, west wind circulation and the Tibetan Plateau circulation can be seen, but the correlation 
between temperature and vapor content before abrupt change points (1961-1984) is not as good as the correlation after the abrupt change points (1985-2010). The correlation between west wind circulation and vapor content after the abrupt change point is a little better than the correlation before the abrupt change point, while the correlation between the Tibetan Plateau circulation and vapor content after abrupt change point is much better than the correlation before the abrupt change point. This means that the west wind circulation is an important factor that affects the abrupt change of surface vapor content, and the Tibetan Plateau circulation is a most important factor that affects the abrupt change of surface vapor content.

Table 2 The correlation coefficients between surface vapor content and climate factors

\begin{tabular}{cccc}
\hline Period & Temperature & $\begin{array}{c}\text { West wind } \\
\text { circulation }\end{array}$ & $\begin{array}{c}\text { Tibetan Plateau } \\
\text { circulation }\end{array}$ \\
\hline 1961-2010 & 0.4191 & 0.3313 & 0.5219 \\
$1961-1984$ & 0.3211 & 0.1626 & 0.0516 \\
$1985-2010$ & -0.0376 & 0.1660 & 0.4689 \\
\hline
\end{tabular}

There was a positive correlation between surface vapor content over the Tarim Basin and the Tibetan Plateau circulation; the correlation coefficient was 0.522 for $1961-2010$, which is significant $(\alpha=0.01)$, 0.052 (small) for 1961-1984, and 0.469 (large) for 1985-2010, which is significant $(\alpha=0.01)$. Based on the studies on the 50-year period (Fig. 5), we found that the variation in the Tibetan Plateau circulation basically agreed with the variation in the vapor content, and the correspondence of their peak-valley values is good, which indicates a close relationship between the Tibetan Plateau circulation and the surface vapor content.

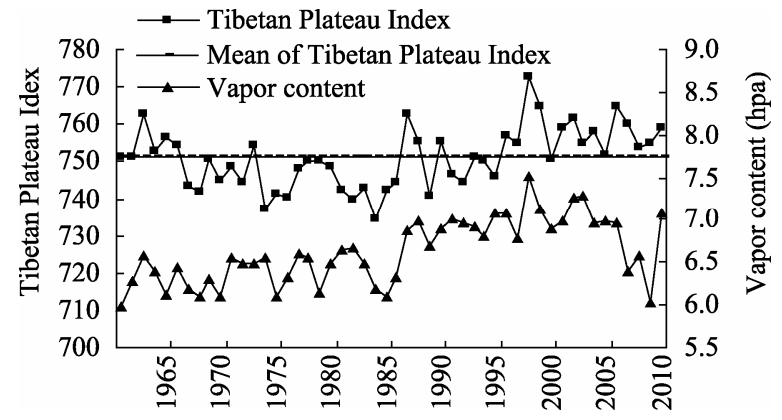

Fig. 5 The variation in the Tibetan Plateau circulation index and surface vapor content in the Tarim Basin

\section{Conclusions}

Our studies based on the data for the last 50 years reveal:

(1) The surface vapor content over the Tarim Basin increased almost consistently with an average trend value of 0.48 . Separately, there were three increasing high-value centers and three increasing low-value centers, which presented an alternative distribution of strips and blocks from northeast to southwest.

(2) There existed notable inter-decadal variations in annual and seasonal surface vapor content over the Tarim Basin during the study period, with more vapor after the mid-1980s and less vapor in the 1960s and 1970s. The significant increase in vapor content contributed to the vapor increase in the 1980s and 1990s. Of the four seasons, the increase trend is strongest in summer, reaching 0.43 , and weakest in spring. There existed a large difference between the spring trend and the annual, summer, autumn and winter trends.

(3) There are clear periods of 4-6 years and 8-10 years in the cycles of annual and seasonal vapor contents in the Tarim Basin, and alternating cycles of less and more amounts of vapor presented. The annual and seasonal vapor contents all changed abruptly and significantly $(\alpha=0.05)$ in the mid-1980s.

(4) The west wind circulation, Tibetan Plateau circulation and the annual mean temperatures are the main factors that influence surface vapor content over the Tarim Basin, and of these the Tibetan Plateau circulation may be the most important contributor.

The decadal change of surface vapor content over the Tarim Basin is influenced by multiple factors, and is, therefore, very complex, and the quantitative contribution of the factors remains to be elucidated by further research. However, the climate wetting as revealed in this paper will increase rainfall and runoff in the Tarim Basin. This is a positive signal to ease the dry state of the basin, but the wetting will also increase the occurrence of heavy rainfall and extreme hydrological events such as floods. The wetting has significant influences on the ecological environment, water resources, agriculture and economic activities in the basin (Xu et al., 2004). How to improve the environment and economic development by using this chance of higher precipitation and what measures 
shall be taken to reduce flood damage from heavy rainfall are issues to be addressed. At present, the priority should focus on strengthening the monitoring and research on the likely duration of this wetter period, better runoff control, and a system of early warning against flood events under the background of climate warming.

\section{References}

Ai W X, Lin X C. 1995. The climatic abrupt change in the Northern Hemisphere for 1920s and 1950s. Acta Meteorologica Sinica, 9(2): 190-198

Chen Y N, Xu Z X. 2004. Assessing possible effects of global climate change on water resources in Tarim Basin. Science in China: Earth Sciences, 34(11): 1047-1053.

China Meteorological Administration. 2003. The Specifications for Surface Meteorological Observation. Beijing: Meteorological Press, 36-40.

Climate Diagnostics and Prediction Division of the National Climate Center. 2008. The circulation index and vectors on 500 hpa in August, 2008. Meteorological Monthly, 34(10): 128-128.

Cui Y Q. 1994. The transport of vapor and its sources in Northwest China. Journal of Hydraulic Engineering, (9): 79-87, 93.

Dai X G, Li W L, Ma Z G. 2007. Water-vapor source shift of Xinjiang region during the recent twenty years. Progress in Natural Science, 17(5): 569-575

Deng Z W, Lin Z S, Zhao X L. 1997. Multiple time scales analysis of $\mathrm{Xi}$ 'an climate change for last 50 years. Plateau Meteorology, 16(1): 81-93.

Ding Y H, Zhang J, Xu Y, et al. 2003. The Evolution and Forecast of Climate System. Beijing: China Meteorological Press, 51-64.

Fan Y T, Chen Y N, Li W H, et al. 2011. Impacts of temperature and precipitation on runoff in the Tarim River during the past 50 years. Journal of Arid Land, 3(3): 220-230.

Fu C B, Wang Q. 1992. The definition and detection of the abrupt climatic change. Chinese Journal of Atmospheric Sciences, 16(1): 111-119.

Hu R J, Jiang F Q, Wang Y J, et al. 2002. A study on signals and effects of climatic pattern change from warm-dry to warm-wet in Xinjiang. Arid Land Geography, 25(3): 194-200.

Huang R H, Chen J L, Liu Y. 2011. Interdecadal variation of the leading modes of summertime precipitation anomalies over Eastern China and its association with water vapor transport over East Asia. Chinese Journal of Atmospheric Sciences, 35(4): 589-606.

Huang R H, Zhang Z Z, Huang G. 1998. Characteristics of the water vapor transport in East Asian monsoon region and its difference from that in South Asian monsoon region in summer. Chinese Journal of Atmospheric Sciences, 22(4): 460-469.

Jian M Q, Qin X H, Qiao Y T. 2006. Spatial and temporal variations of

\section{Acknowledgements}

This research was supported by the National Natural Science Foundation of China (40975097), National Basic Research Program of China (2010CB951001) and the Special Fund for Public Welfare Industry (Meteorology) (GYHY 201006012).

large-scale atmospheric water resources over southern China. Acta Scientiarum Naturalium Universitatis Sunyatseni, 45(6): 97-101.

Jiang F Q, Yang Y H. 2004. Potential links of flood and drought disasters in Xinjiang to some larger scale climatic driving forces. Arid Land Geography, 27(2): 148-153.

Kalnay E, Kanamitsu M, Kistler R, et al. 1996. The NECEP/NCAR 40 year reanalysis project. Bulletin of the American Meteorological Society, 77: 437-471

Karalis J D. 1974. Precipitable water and its relationship to surface dew point and vapor pressure in Athens. Journal of Applied Meteorology and Climatology, 13(1): 760-766.

Li D L, Xie J N. 1997. A study of summer precipitation features and anomaly in Northwest China. Chinese Journal of Atmospheric Sciences, 21(3): 331-340.

Li H J, Li J, He Q. 2008. Study on sandstorm trend and abrupt change in Xinjiang. Journal of Desert Research, 28(5): 915-919.

Li W L, Wang K L, Fu S M, et al. 2008. The interrelationship between regional westerly index and the water vapor budget in Northwest China. Journal of Glaciology and Geocryology, 30(1): 28-34.

Lin X C. 1998. Climate Change and its Influence at the End of the 1970s and Beginning of the 1980s. Beijing: Metrological Press, 15-16.

Lin Z Y, Zhen D. 1992. The tracks of moisture transportation and its vapor geo-ecological characteristics on Qinghai-Xizang Plateau. Arid Zone Research, 9(2): 1-7.

Liu W, Xu Y P, Huang Y. 2005. Effects of global warming on precipitation and runoff volume in Xinjiang. Arid Land Geography, 28(5): 597-602.

Lv S N, Li D L, Wen J, et al. 2010. Analysis on periodic variations and abrupt change of air temperature over Qinghai-Xizang plateau under global warming. Plateau Meteorology, 29(6): 1378-1385.

Niu C W, Zhang L P, Xia J. 2004. Wavelet analysis on the precipitation in North China. Arid Land Geography, 27(1): 66-70.

Partal Turgay, Ercan Kahya. 2006. Trend analysis in Turkish precipitation data. Hydrological Processes, 20: 2011-2026.

Qian Z A, Wu T W, Liang X Y. 2001. Feature of mean vertical circulation over the Qinghai-Xizang Plateau and its neighborhood. Chinese Journal of Atmospheric Sciences, 25(4): 444-454.

Shi N, Chen L W. 2002. The secular variation of global land annual rainfall fields from 1948-2000. Chinese Science Bulletin, 47(21): 
1671-1674.

Shi Y F, Shen Y P, Hu R J. 2002. Preliminary study on signal impact and foreground of climatic shift from warm-dry to warm-humid in Northwest China. Journal of Glaciology and Geocryology, 24(3): 219-226.

Wang K L, Jiang H, Zhao H Y. 2006. Advection and convergence of water vapor transport over Northwest China. Advances in Water Science, 17(2): 164-169.

Wang X L, Wen Q H, Wu Y. 2007. Penalized maximal t-test for detecting undocumented mean change in climate data series. Journal of Applied Meteorology and Climatology, 46(6): 916-931.

Wang X R, Xu X D, Miao Q J. 2003. Regional characteristics of summer precipitation and water vapor amount in Northwest China. Climatic and Environmental Research, 8(1): 35-42.

Wang Y R, Lin S, Li Y H, et al. 2006. Response of atmospheric vapor over Gansu province to global climate change. Arid Land Geography, 29(1): 47-52.

Wei F Y. 1999. Statistical Diagnosis and Forecast Methods in Modern Meteorology. Beijing: Meteorological Press, 53-59, 106-113.

Wei Z G, Dong W J, Hui X Y. 2000. Evolution of trend and interannual oscillatory variabilities of precipitation over Northwest China. Acta Meteorologica Sinica, 58(2): 234-243.

$\mathrm{Xu} \mathrm{G} \mathrm{H,} \mathrm{Lu} \mathrm{G} \mathrm{Y.} \mathrm{2004.} \mathrm{Research} \mathrm{of} \mathrm{climate} \mathrm{change} \mathrm{and} \mathrm{ecological}$ environment in Xinjiang. Bimonthly of Xinjiang Meteorology, 27(2): 1-4.

$\mathrm{Xu}$ S Y. 1958. Water vapor transportation and water balance in China. Acta Meteorologica Sinica, 29(1): 33-43.

Yang J M, Qiu J H. 2002. A method for estimating precipitable water and effective water vapor content from ground humidity parameters. Chinese Journal of Atmospheric Sciences, 26(1): 9-22.

Yu Y X, Wang J S, Li Q Y. 2003. Spatial and temporal distribution of water vapor and its variation trend in atmosphere over Northwest China. Journal of Glaciology and Geocryology, 25(2): 149-156.

Zhang X W. 2004. A relationship between precipitable water and surface vapor pressure. Meteorological Monthly, 30(2): 9-11.

Zhou T J, Yu R C. 2005. Atmospheric water vapor transport associated with typical anomalous summer rainfall patterns in China. Journal of Geophysical Research, 110: D08104.1-D08104.10. 